\title{
Cameroon Pidgin English at the Service of Local Culture, Science and Technology
}

\author{
Valentine Njende Ubanako \\ Department of Bilingual Studies, the University of Yaounde 1, Cameroon
}

Email address:

ubaval@yahoo.com

\section{To cite this article:}

Valentine Njende Ubanako. Cameroon Pidgin English at the Service of Local Culture, Science and Technology. International Journal of Language and Linguistics. Vol. 3, No. 6, 2015, pp. 510-515. doi: 10.11648/j.ij11.20150306.35

\begin{abstract}
Despite divergent views about the status of Cameroon Pidgin English (henceforth CPE), some researchers such as Atechi (2011); Chia (1983); Mbangwana (2004) etc. are nevertheless unanimous that the language is the most widely spoken lingua franca in the country. Kouega (2008), came up with a dictionary of Cameroon Pidgin English to buttress the fact that it is an autonomous language which has attained maturity. Alobwede (1998: 54) carried out a survey on the acquisition of Pidgin English and English as a first language in some major towns in Cameroon and indicates that CPE is the majority language in Bamenda, Mamfe, Kumba, Buea, Limbe, Douala and Yaounde when compared to the acquisition of English. Equally, Mbangwana (2004:23) posits that 97.8\% Anglophone and 61.8\% francophone Cameroonian urban dwellers speak CPE. From the statistics above, it is evident that more people are proficient in CPE, feel at home with it, and use it more than the official languages (English and French). Consequently, most cultural, scientific and technological knowledge is concealed from the majority of speakers since it is essentially available in English or French, languages they are not very conversant with. In this paper, I am examining how widespread CPE is, as well as the potential and capacity of the language in expressing local cultural, scientific and technical knowledge and how such knowledge could be captured in CPE. Data will be collected through participant observation, literary works of arts, local newspapers published in English and from Kouega's (2008) dictionary on Cameroon Pidgin English. The data will be analysed using the Domain Analysis approach propounded by James Bradley (1980).
\end{abstract}

Keywords: Lingua Franca, Potential and Capacity, Majority Language, Local Culture, Knowledge

\section{Introduction}

Cameroon has been described as the most linguistically complex country in Africa (Tadadjeu, 1983) and on the basis of its linguistic, cultural and climatic diversity, has been referred to by many scholars and researchers as Africa in miniature. Ethnologue (2005) puts the number of home languages at 279 alongside Pidgin English and the two official languages (English and French). When the Europeans first came to the coast of Cameroon, communication between them and the indigenous people was ensured through pidginized English. Cameroon Pidgin English has thus continued to adapt itself to the changing sociocultural, scientific and technological context of Cameroon.

The world is changing rapidly in terms of technology and the question of appropriate terminology to disseminate these developments become very acute in a multilingual and multicultural country like Cameroon where less than $30 \%$ of Cameroonians are educated in the European languages
(English and French) which are used officially in the country, meaning that not up to one third of the population understands scientific and technological terms and expressions which essentially have European languages as modes of expression. Cameroon Pidgin English therefore, positions itself as that language which can be said to be representative of the Cameroonian society and beyond, consequently, it is the most appropriate language in the creation, adaptation and dissemination of local culture, science and technology. CPE is thus considered by many in Cameroon as their language and they claim ownership of it and consider English and French used as official languages in the country as foreign. This goes to strengthen Chumbow's (1995:51) observation that "The acceptability, adoption and assimilation of new knowledge in science and technology by the masses of the rural population, will be enhanced if made available in the language they know best, rather than in an exoglossic or foreign language, as is often the case".

Writers and scholars from all regions of Africa meeting in 
Eritrea, 11-17 January 2000 made a ten point declaration in what is today known as the Asmara Declaration on African languages and literacy. Article 7 states: "The effective and rapid development of science and technology in Africa depends on the use of African languages and modern technology must be used for the development of African languages". This can equally be extended to CPE which is the language spoken and understood by the large majority of Cameroonians as indicated by the statistics above and who claim ownership of it.

Cameroon Pidgin English has been able to submit itself to different kinds of uses in Cameroon and thus stands tall as the language par excellence for the dissemination of local culture, science and technology. Other studies such as Widdowson (1994), Norton (1997), Higgins (2003) have highlighted how different users have appropriated English, altered it to fit their different local contexts and respond to their different needs.

Many studies carried out have highlighted the educational potential of CPE Atechi (2011); the commercial and social potential Mbangwana (2004), the political potential Ubanako (2008) but the cultural, scientific and technical potential of $\mathrm{CPE}$ has seldom been given the attention it deserves.

This paper therefore seeks to investigate how widespread $\mathrm{CPE}$ is, the potential of the language in expressing local culture, science and technology as well as the main domains and sources of such terms and expressions.

Data will be collected through participant observation, interviews, literary works of art and local newspapers published in English from those who, in the course of their different activities, use CPE. Specifically, 50 participants who understand and use cultural terms, 50 in the domain of local science and technology will make up the main informants.

The data will be analysed using the Domain Analysis approach propounded by James Bradley (1980) which analysis the language of people in a cultural context and describes how social and cultural situations interrelate with cultural meanings. After the collection of the different terms and expressions which fall under the local, scientific and technological domains outlined above, they will be classified under broad domains in order to account for their lexical and semantic features as well as the sources of such terms and expressions.

In the first part of the paper, we present the potential of $\mathrm{CPE}$ in terms of its spread and functions over time. In the second part of the paper, we examine the sources of CPE terms and expressions and examine the contribution of each of the background languages to the development of local, scientific and technological vocabulary in the corpus. In the third part, we classify the terms and expressions into the broad domains of local culture and science and technology and account for the social and cultural meanings within the local setting. In the fourth and last part, we examine the expressiveness of the selected CPE terms and expressions vis-à-vis their standard English equivalents. In the fifth and last part, we present some major findings.

\section{The Power of CPE: An Overview}

Within the complex linguistic situation of Cameroon, Pidgin English is one of the languages with numerous uses and functions. The language has over the years, known different appellations by different scholars and researchers. These include Cameroon Creole (Schneider, 1960); Cameroon Pidgin English (Menang, 1979); Cameroon Pidgin (Todd, 1982); Kamtok (Ngome, 1986); Camspeak (Tiayon, 1985) and many others. Pidgin English was first spotted in the $17^{\text {th }}$ century when it competed with Pidgin Portuguese. By the $18^{\text {th }}$ century, it had become a widely used and very important language in the West African Coast in the domains of trade and evangelisation. During the German and FrancoBritish colonial era, the language thrived as the colonial administrations, despite an earlier banning especially by the Germans, realised the use and vitality of the language. Today, the language has become a veritable identity marker especially among English-speaking Cameroonians. Considering the popularity of the language (used in music, churches, law courts, markets etc.), the language has also become popular among Francophone Cameroonians. Considering the fact that the importance and role of Pidgin English has been acclaimed in different places such as in Papua New Guinea where the language has been given official status despite the fact that it is spoken by an estimated 400000 people, it were high time the language, whose importance and role cannot be over emphasised in Cameroon, be given some due consideration.

There have however, been two different perceptions about Pidgin English among scholars in Cameroon with one group viewing the language as a separate language in its own right and another positing that it is part of a continuum with at the extreme end, an acrolectal, then a mesolectal and finally a basilectal variety. Also, overtime, due to contact and exposure, different researchers have been quick to point out that CPE has witnessed the emergence of different varieties. Despite these different varieties, the internal stability of CPE is not threatened and there are no foreseeable problems of unintelligibility.

Other researchers have equally highlighted the importance and place of Pidgin English in Cameroon. Despite their divergent views about the status of the language, they are however unanimous that CPE is the most widely spoken lingua franca in Cameroon. Povey (1983) considers CPE the most widely spoken and used language in the country. Mbangwana (1983:90) considers it a 'nonethnic language' thereby arguing that the language has a national character, while Chumbow and Simo (1996:419) point out that the language, more than any other, can solve the communication needs of Cameroonians. Although Todd and Jumbam (1992) put the number of speakers of CPE at 6 million, there is the belief that this is mere speculation considering the increased number of Nigerians and Francophone Cameroonians who speak the language today. Echu (2008) notes that figures from the Nigerian Embassy in Yaounde in 2005 indicated that there were between 2.2 
and 3 million Nigerians in Cameroon. Considering the fact that almost all of these Nigerians speak Pidgin English, the total number of speakers in Cameroon may well attain 10 million today. Schneider (1966: 5) reports that in the midsixties, $85 \%$ of CPE terms came from English, $13 \%$ from indigenous languages and 2\% from other languages including French and Portuguese. Later on in the seventies, the situation had changed as pointed out by Mbassi-Manga (1973). According to him, $80 \%$ of the vocabulary items of CPE came from English while 14\% came from indigenous languages, 5\% from French and 1\% from other languages. Atechi (2011) notes that the language should be given the kind of recognition enjoyed by English and French and should be used as a medium of instruction considering the potentials it has. Todd (1982:25) also lauds the educational potential of CPE in the following terms:

...Camp may, in the future, be considered as a possible language of education...There are many strong reasons which can be given in support of the use of CamP as a medium of instruction. It is the most widely understood language in the region; it is structurally close to the vernaculars which are also reflected in its calques and idioms and it is not specifically associated with one tribe or one religion. It is also being used as a vehicle for Cameroon culture and for Christian doctrine and is, in addition, mutually intelligible with Nigerian Pidgin English. There would thus be few linguistic or financial difficulties associated with its adoption as a medium of education.

Chia (1983) notes that Pidgin English is not only widely spoken but it is a very popular language in Cameroon. It is thus the most important contact language in the country and the language which is closest to the people. It is equally very dynamic and therefore has the capacity to conveniently respond to the scientific and technological needs of its users not only in Cameroon but across West Africa, since CPE shares many characteristic features with other West African Pidgins, making it stand tall as a veritable trans-border and transnational medium of communication within the Central/West African sub region. Despite the marginal treatment of the language and negative attitudes observed; some researchers consider it as a 'bastard language'; an impediment to attaining Standard English; considering whether it should be banned or not (Alobwede, 1998); others claim it is facing death (Kouega, 2001); while others consider it the language of the under educated and consequently not thought to be of any real use or capable of contributing to any meaningful development. All the negative attitudes outlined above notwithstanding, the language is expanding in lips and bounds and its functions increase every day.

Alobwede (1998:54) carried out a survey on the acquisition of English and Pidgin English as a first language in some major towns in Cameroon and presents the following statistics:
Table 1. Acquisition of English and Pidgin English.

\begin{tabular}{lll}
\hline & English & Pidgin \\
\hline Bamenda & $3.5 \%$ & $24 \%$ \\
Mamfe & $1 \%$ & $25 \%$ \\
Kumba & $3 \%$ & $22 \%$ \\
Buea & $13 \%$ & $28 \%$ \\
Limbe & $9 \%$ & $30 \%$ \\
Douala & $6 \%$ & $10 \%$ \\
Yaounde & $8 \%$ & $15 \%$ \\
\hline
\end{tabular}

From the table above, it is clear that CPE is more popular than English, meaning that the people find it a more convenient mode of expression. Considering the functions ( used for commercial transactions, cultural ceremonies, arts and music, science technology etc.) and spread (used by different people in different places even across the borders) of the language therefore, it positions itself as the language par excellence for the dissemination of local culture, science and technology in a complex multilingual and multicultural State like Cameroon.

\section{Domains of Use}

The domains of use of Cameroon Pidgin English are diverse. It is used in politics, the audio visual media, in church, in the market and for different social and cultural interactions. For the purpose of this paper, I am going to consider the following domains: local culture and local science and technology.

\subsection{Local Culture}

Local culture has contributed immensely to the development and spread of CPE terms and expressions. It is no longer a debate that CPE has the ability and capability of capturing and expressing local culture more than English or French used in Cameroon. The domains of ethnic or cultural manifestations in CPE include: music and art, literature, diets, fashion, kinship etc. Mbangwana (1992:96) had earlier pointed out that some terms are "English only in form but essentially Cameroonian in mood and content". The following terms and expressions therefore succinctly paint the specific sociocultural environment of Cameroon and the terms have been created and adapted to the environmental needs and realities of the users:

Red feather cap-An honorific distinction (red feather placed on a cap) in the grassfield region of Cameroon.

Born house-A ceremony to celebrate the birth of a new child.

Bend-skin-A kind of traditional dance.

Agbada-A type of flowing dress for men.

Ambasibe-Traditional music and dance among the Bassa in Cameroon.

Asso-A customer.

Bikutsi-Music and dance among the Beti.

Manyi-A mother of twins.

Tanyi-A father of twins

Bitter leaf soup-A kind of soup prepared from leaves 
which originally have a bitter taste.

Bottle dance- A traditional dance/music where the main instrument used is the bottle.

Come no go-Settlers who have moved to a place and decided to stay there.

Nchinda-The aid to the traditional ruler.

Ngumba-Nobility title in the North West Region.

Njangi-Traditional loan scheme.

Kwifon-Security agent of a traditional ruler.

Nkang-Corn gruel.

Ashia-Word to express sympathy or compassion.

Chop chair-A successor.

Mbanga soup-A traditional sauce prepared with palm nuts.

Die house-A home where death has occurred.

Knock door-Betrothal ceremony to express wedding intensions.

Cry die-Ceremony to remember the dead.

Njanga-A particular kind of fish which is particularly small in size.

Pepper soup-A kind of sauce prepared with a lot of pepper. Okrika-Used clothes.

Takumbeng-A secret society of women in the North West Region.

King maker-A person who is among those who crown a traditional ruler.

Nkeng- Peace plant.

The terms above culled from daily use by speakers indicate that $\mathrm{CPE}$ an efficient medium of transmitting culture. In fact, judging from the examples above, the terms and expressions reflect the diverse cultural heritage of Cameroon which are used and better understood by CPE users more than any other users.

\subsubsection{Expressive Nature of CPE Terms}

Some CPE terms are very expressive as they tend to capture the situation and make it more perceivable and palpable. Users of CPE have thus adapted the language to reflect the socio-cultural, scientific and technological situation of Cameroon and respond conveniently to the communicative needs of its users. Examples include the following:

Woman dog-Bitch. Woman (female) dog.

Pikin dog -Puppy. Pikin refers to child/young in CPE. Hence, the 'child of a dog'.

Trouble bank-Assistance fund instituted in social and cultural associations when 'trouble' occurs e.g. death, ill health, accident etc.

Cutting grass-Hedgehog. (Known for the manner in which it cuts grass and uses it for food and shelter)

Bush meat-Game. (Coming from the bush/forest as opposed to those reared at home e.g. cow, goat etc.)

Bush pig-Boar. (Coming from the bush as opposed to the pig reared at home)

Bush fowl-Partridge. (Coming from the bush/forest as opposed to the fowl reared at home)

Bride price-Money and property given to bride's family in exchange of the bride.
Yellow soup-A traditionally prepared soup which is yellow in colour.

Chicken parlor-A place where cooked or fried chicken is sold together with beer, a place of merrymaking and relaxation.

Buyam sellam-Food crop retailer. (who actually buys and sells)

The terms above which have equally come from daily use, point to the fact that some CPE terms capture and express certain realities better than existing Standard English equivalents which sometimes appear exoglossic and fail to reflect the socio cultural and environmental realities of Cameroon. Considering the large number of speakers of CPE as opposed to those who speak English or French, it becomes clear that CPE has adapted to the unique circumstances of its speakers and thus should be used and encouraged. The examples above; woman dog, trouble bank, bush pig, yellow soup, for example, are more expressive and appeal to the realities of the users 'owners' of CPE when put side by side with their standard English equivalents.

\subsubsection{Sources of Terms and Expressions}

Most CPE terms and expressions are a reflection of the complex linguistic situation of Cameroon. They have thus come as direct borrowings, loan translations, coinages, creation of neologisms, semantic allocations, transfers and shifts from background languages in Cameroon especially from home languages and CPE. In order to better account for the different sources of CPE terms and expressions, I am going to categorise them in terms of different domains of use, namely, local culture, local science and local technology.

The table below presents the contributions of different background languages to the different terms and expressions in the corpus:

Table 2. Domain of Local Culture.

\begin{tabular}{lll}
\hline Language & Number of occurrence in Corpus & Percentage \\
\hline Home languages & 15 & $37.5 \%$ \\
French & 01 & $02.5 \%$ \\
CPE & 24 & $60 \%$ \\
Camfranglais & 00 & $00 \%$ \\
TOTAL & 40 & $100 \%$ \\
\hline
\end{tabular}

Out of the total number of 40 items in the domain of local culture in the corpus, 15 are from local languages accounting for $37.5 \%$ while 24 are from CPE representing $60 \%$. There was one item from French representing $02.5 \%$ and no item from Camfranglais giving $00 \%$. The statistics above indicate that $\mathrm{CPE}$ positions itself as the highest contributor in the domain of local culture and thus indicating that the language has a very high potential in expressing local culture more than any other background language in Cameroon.

\subsection{Local Science and Technology}

Local science is aptly represented in CPE and this cuts across the domains of local medicine, agriculture, brewery, local furniture, construction etc. It is important to note that 
more than $90 \%$ of those who practice local science and technology have never been formally trained or have received very limited training in the official languages, but rather, master CPE which they use every day. In this category, we can cite the examples below:

Ancara- A farming practice believed to increase yield and productivity through the burning of the earth.

Bili bili -Locally brewed alcoholic drink through a method of fermentation.

Country kanwa-A product made from wood ash and used to prepare 'yellow soup'.

Fever grass-Lemon grass believed to be efficient against fever.

King grass-A particular kind of grass with mystical powers.

Lion kola-A kind of kola which has medicinal properties.

Bitter kola-A kind of fruit believed to be efficient against stomach ache and increase virility.

Black stone-A particular kind of black stone which is believed to be efficient against snake bites.

Black medicine-A kind of black powder believed to cure stomach ache.

Kwacha-Locally produced drink from fermented corn.

Shia-Locally produced drink from corn.

Mbuh -Locally produced drink.

Bamboo bed-Locally made bed from bamboo.

Bamboo cupboard-Locally made cupboard from bamboo.

Bamboo motor-Locally fabricated car from bamboo.

Afofo-Locally brewed alcoholic drink.

Corn beer-Locally brewed drink from corn.

Palm wine-Locally tapped drink from the palm.

Grinding stone-A stone with a flat surface used for mashing and grinding spices and other ingredients.

Raffia palm wine-Locally tapped drink from raffia palm.

Country garden egg-A kind of garden egg with a special taste.

Agric fowl-Improved variety of chicken.

Canda stick-A particular tree back which is believed to have medicinal properties.

Carter-Support made from cloth, leaves or grass to ease the carrying of heavy load on the head.

Potopoto house-Locally built house with mud.

Alligator pepper-A special kind of pepper believed to have mystical powers

Odontol-Locally distilled drink (synonymous with afofo).

Slow poison-Euphemistic appellation of HIV Aids.

God fire-Rashes on the skin which sometimes indicates the presence of a sexually transmitted disease.

Sugar sugar-A venereal disease.

Come no go-Skin rashes that take long to go away.

Kenja-Locally made basket used for the transportation of food and other items.

Cane chair-Chair made from a particular kind of tropical plant.

Country bag-Locally made bag made from raffia fibre.

Cane cupboard- Chair made from a particular kind of tropical plant.
Banda-Locally fabricated ceiling, usually with bamboo for drying and preserving cereals

Country torch-Locally made torch light from bamboo.

Rubber ball-Ball made from locally produced rubber.

Country groundnut-A peculiar species of groundnut.

Masepo-A special kind of herb with medicinal and culinary properties

A close look at the examples above indicates that all the words and expressions which fall under local science and technology reflect the expressiveness of local science through CPE as the users have been able to appropriate local science and technology and adapted it to their local realities. This equally goes to point out that lexical technical and scientific knowledge can be appropriately captured in CPE.

Table 3. Domain of Local Science and Technology.

\begin{tabular}{lll}
\hline Language & Number of occurrence in Corpus & Percentage \\
\hline Home languages & 05 & $12.5 \%$ \\
French & 00 & $00 \%$ \\
CPE & 35 & $87.5 \%$ \\
Camfranglais & 00 & 00 \\
TOTAL & 40 & $100 \%$ \\
\hline
\end{tabular}

From the table above, out of the total of 40 words in the domain of local science and technology, 05 terms and expressions representing $12.5 \%$ have come from home languages while 35 have come from CPE accounting for $87.5 \%$. No term or expression came from the other background languages. This is once more a clear indication that CPE apart from being the highest contributor to the development of local scientific and technological vocabulary, has proven to be a reliable medium and vector for the dissemination of local technology and science.

\section{Conclusion}

From the above, it is evident that $\mathrm{CPE}$ has the potential and resources and consequently, can express local culture, science and technology more than any other language in the complex multilingual and multicultural situation of Cameroon. Considering the number of users of $\mathrm{CPE}$ which is continuously on the rise, it is clear that the use of such terms goes a long way to facilitate communication in an informal setting like Cameroon.

The CPE terms and expressions outlined above should not be considered wrong but instead as preferred ways to express reality by a given community since language is used to serve the people and they are the beneficiaries. Hence, communication is more effective when CPE terms are used and this helps to bridge the gap between the users and their immediate environment.

The data presented here points to that fact that some terms and expressions used are generally culture specific and reflect the environmental realities of the users as opposed to some SBE equivalents which are sometimes appear exoglossic and present realities which do not readily appeal to the needs and immediate physical environment of the 
users. This further buttresses the fact that CPE can be used in diverse domains including culture, business, politics, technology etc.

Local culture, science and technology terms and expressions come from specific sources which reflect the linguistic background of Cameroon. The terms and expressions have come from other background languages such as French, Standard English, Camfranglais but CPE remains the greatest contributor as far as local, scientific and technological terms are concerned. The terms and expressions have been named through different strategies, prominent among which are those outlined by Anchimbe (2004); naming through colour, taste, physical or behavioural nature, contrastive juxtaposition with another element and analogy with other words.

We can thus talk of an authentic local science and technology which has gone a long way to contribute to the scientific and technological landscape of the areas where CPE is used and which of course, it better understood by many than the sometimes high sounding Standard English equivalents. The language therefore has the potential of being used in literacy programmes considering the number of people who use the language in Cameroon and across West Africa. Thus, if any society intends to advance scientificotechnologically, it has to use the language of the masses.

\section{References}

[1] Anchimbe, E. (2004) "Creating new names for common things in Cameroon English". The Internet TESL Journal, X(8), August 2004. http://iteslj.org/Articles/AnchimbeCameroonEnglish.html.Creating New Names for Common Things in Cameroon English.

[2] Atechi, S. (2011). "Pidgin English in Cameroon: To teach or not to teach". In International Journal of English Language Studies (IJLS), Vol 5(1). 53-66.

[3] Atechi, S. (2011). "Is Cameroon Pidgin flourishing or dying?" English Today, 27 (3), pp.30-34.

[4] Ayafor, M. (1996). "An orthography for kamtok." English Today, 48, Vol. IV, pp.53-57.

[5] Chumbow, B.S. \& Simo Bobda A. (1996). The Life-Cycle of Post-Imperial English in Cameroon. In Joshua A. Fishman, Andrew W. Conrad \& A. Rubal-Lopez (eds) Post Imperial English: Status Change in Former British and American Colonies, 1940-1990 (Contributions to the Sociology of Language, 72) Berlin: Mouton de Gruyter, pp. 401-429.

[6] Chumbow B. S. (1995) "The Language Factor in the Development of Science and Technology in Africa". Paper Presented at the Human Sciences Research Seminar, Cape Town and Pretoria, 24-27 March 1995.
[7] Echu, G. (2008) "Forms of address as a politeness strategy in Cameroon Pidgin English" In Bernard Mulo Farenkia (ed). Linguistic Politeness in Cameroon: Pragmatic, Comparative and Intercultural Approaches. Frankfurt: Peter Lang, pp 311323.

[8] Ethnologue (2005). Languages of the World. (Available from: http://www.ethnologue.com.).

[9] Fonka, H. (2011). "Cameroon Pidgin English: Evolution in Attitudes, Functions and Varieties". Unpublished PhD Thesis. University of Yaounde.

[10] Higgins, C. (2003) 'Ownership' in the outer circle: An alternative to the NS-NNS dichotomy. TESOL Quarterly 37 (4), 615-644.

[11] Kachru, B.B (1986) The Alchemy of English. Urbana, IL: University of Illinois Press.

[12] Kouega, J.P. (2001). "Pidgin English Facing Death in Cameroon." Terralingua. Hancock, pp.11-22.

[13] Kouega, J.P (2008) "A Dictionary of Cameroon Pidgin English Usage: Pronunciation, Grammar and Vocabulary". Lincom Studies in Pidgin \& Creole Linguistics. Munich: Lincom Europa.

[14] Mbangwana, P. (1992) Some Grammatical Sign-Posts in Cameroon Standard English. In Schmied (ed) English in East and Central Africa. Bayreuth: Bayreuth University Press, p93102 .

[15] Mbangwana, P. (2004). "Pidgin English in Cameroon: A Veritable Linguistic Menu." In Africa meets Europe: Language Contact in West Africa._George Echu and Samuel Gyasi Obeng (eds), Nova Science publishers, inc. pp.23-44.

[16] Norton, B. (1997) Language, Identity and Ownership of English. TESOL Quarterly 31 (3), 409-429.

[17] Spradley, J. (1980) Participant Observation. New York: Holt, Rinehart and Winston.

[18] Strevens, P. (1992) English as an International Language: Directions in the 1990s. In B.B. Kachru (ed) The Other Tongue $\left(2^{\text {nd }}\right.$ edn) pp 27-47. Urnana: University of Illinois Press.

[19] Tajfel, H. and Turner, J. C. (1986). "The social identity theory of inter-group behavior". In S. Worchel and L. W. Austin (eds.), Psychology of Intergroup Relations. Chicago: NelsonHall.

[20] Tiayon, C. (1985) "Camspeak: A Speech Reality in Cameroon". Unpublished Maîtrise Dissertation, University of Yaounde.

[21] Widdowson, H. (1994) The Ownership of English. TESOL Quarterly 28 (2), 377-388. 